\title{
Multimedia Study Aids in Teaching Creative Foreign Language Reading: Personal-Activity Approach
}

\author{
Larisa G. Vikulova (a), Svetlana A. Gerasimova (b), Irina V. Makarova (c), \\ Ekaterina M. Vishnevskaya* (d)
}

(a) Moscow City University, 129226, Moscow (Russia), 4-1, $2^{\text {nd }}$ Selskokhoziastvenny Proezd

(b) Moscow City University, 129226, Moscow (Russia), 4-1, $2^{\text {nd }}$ Selskokhoziastvenny Proezd

(c) Moscow City University, 129226, Moscow (Russia), 4-1, $2^{\text {nd }}$ Selskokhoziastvenny Proezd

(d) Moscow City University, 129226, Moscow (Russia), 4-1, $2^{\text {nd }}$ Selskokhoziastvenny Proezd

kate.vishnevsk@ya.ru

\begin{abstract}
The paper covers developing and testing experience of interactive multimedia educational content designed for teaching creative foreign language reading. The article shows how students can develop their creative skills which manifest themselves when students try to make their own intellectual and informational content based on what they have read. We prove that as an educational resource an individually oriented study aid can be considered as a base that extrinsically motivates students to study foreign languages in higher school. As a topical issue we see web-based creative reading within the framework of collaborative educational setting led by personal-activity approach that prompts students to be actively involved in the educational process. Interactive multimedia online boards have become the primary focus of the paper. They contribute to building up collaborative learning environment and facilitate the development of the new teaching organizational forms. The paper contains several student cooperation formats on creative reading of the philosophical novella "The Little Prince" by Antoine de Saint-Exupéry while using multimedia study aids on the Miro interactive whiteboard.

Keywords: collaborative educational, electronic learning resource, multimediality, creative reading.
\end{abstract}

(C) 2021 Larisa G. Vikulova, Svetlana A. Gerasimova, Irina V. Makarova, Ekaterina M.

Vishnevskaya

This is an open access article distributed under the terms of the Creative Commons Attribution License (CC BY 4.0), which permits unrestricted use, distribution, and reproduction in any medium, provided the original author and source are credited.

Published by Moscow City University and peer-reviewed under responsibility of TSNI-2021

(Textbook: Focus on Students' National Identity)

\section{Introduction}


Due to the modernization of higher education a strong emphasis is placed on the quality of the educational process. When implementing an educational program, teachers tend to turn to different educational aids within the learning process, e.g. study aids. Such an educational material is characterized by its social and functional nature, i.e. it is meant to help learn and teach various subjects, acquire additional information due to the large study text volume and large number of assignments, which allows students to expand, deepen and better absorb the knowledge for a particular subject (Ovchinnikova, 2012).

\section{Purpose and objectives of the study}

The goal of the paper is to linguodidactically substantiate content-structural features of a study aid for creative reading in French within the framework of a collaborative educational setting.

The key objectives are as follows:

- to help students develop ICT competence in the process of collaborative training for networking in the context of project work;

- to provide students with an opportunity to develop their creative skills which manifest themselves when students try to make their own intellectual and informational content based on what they have read.

As of today, in spite of the existing research base, we do not see a comprehensive framework describing the practical use of an innovative study aid on creative foreign language reading that would correspond with students' interests and needs while at the same time ensuring their (students') direct involvement in compiling such a study book.

Meanwhile, the use of an individually oriented study aid is extremely relevant at the current stage of linguodidactics as such a study book would help overcome a number of substantial contradictions in foreign language (FL) teaching. Some of the contradictions are as follows:

- a social demand for providing language school graduates with communication skills to use in business surroundings and the lack of individually oriented strategies for students' personal development when relying on a uniform study material from the study aid;

- the relevance of a study aid as a form of a study book which solves issues that play a major role in developing independence and moral strength in students, as well as the lack of conditions for its implementation according to the personal-activity approach. 
The search for a way to overcome these contradictions poses a key problem of our paper and begs the following question: how can we ensure that a highly qualified professional is properly trained for the communication within business surroundings with the help of an innovative study aid?

\section{Literary Review}

Modern education is focused on developing general and professional personal culture of a prospective specialist, which calls for a new approach in foreign language teaching. Specifically, information technologies introduction into modern education system promotes efficiency of the educational activity as well as improves the quality of specialist training that corresponds to the requirements of the information society. The challenges of the digital transformation in education have been in the focus of research attention especially in the last decades due to flourishing multimedia era. The authors investigate and apply different apps to foster collaborative learning and study digital transformation in collaborative content development. (Auer \& Tsiatsos, 2019).

It is obvious that we have to consider changes in the educational setting including current trends in informatization of education, when the requirements to individual, general cultural and communicative skills of a teacher in specialist training are significantly raised. The issue of modernizing the syllabus and applying new didactic approaches and principles becomes more acute. Within the current framework, without competence-based study aid we are not able to achieve the key goal of the foreign language teaching, which ensures development of a communicative competence in a student, thus facilitating successful communication, fulfilment of professional needs with regard to globalization processes and mobility of the modern society. According to Courtney B. Cazden communicative competence implies a knowledge of both linguistic and sociolinguistic rules: a knowledge, in other words, both of language (in the narrow sense of phonology, syntax and semantics) and of the social world in which it must be used (Cazden, 2017).

The contents of such an aid mainly include social information resulted from the public activity, which allows us to view the aid as a relatively independent social phenomenon that plays a major part in raising educational and cultural standards of the modern society. The practical nature of the study aid shows that its content covers subject knowledge as well as specific areas of cognitive activity where this knowledge serves as one of the key components (Sakharova, 2007).

Therefore, the scientific educational community raises the question of "optimistic projection" in developing linguistic educational practices (Tareva, 2015; Tareva \& Tarev, 2018), including WEB-technologies which 
expand the range of educational activities and ensure conditions for exploring new organizational forms and methods of foreign language teaching. Thus, it is essential to create and implement a study aid that would be tailored to the needs of every student and would be flexible in regards to the student's individual characteristics. A particular study aid has to transform from a universal study book into a unique "route" for each student that would follow their personal development and help form individually distinct communication skills.

\section{Methodology}

Methodological framework of the research is based on one of the fundamental approaches used in modern educational system, a personal-activity approach that relies on the autonomy of the student (O.A. Gavrilyuk, S.V. Dedushkina, V. Liquette and Y. Maury, D. Toruç, etc.). Such an approach allows students to carry out their projects and achieve their life goals, as only then students would have an opportunity to contemplate, plan, analyze, compare and assess their knowledge and achievements, which would ensure their success in social life (Toruç, 2013). In this case, the personal-activity approach helps attain higher personal (in regards to the student) development potential of the foreign language study aid (Tareva, 2007).

One of the key methodological problems is the issue of how to organize and structure knowledge and compile a foreign language study book (E.G. Tareva, L.G. Tyurina, L.M. Orbodoeva, N.V. Popova, Ch. Puren, E. Riquois, D. Toruç, etc.). The most crucial issues are how students make sense of the study material and understand it, asses its relevance and value. Educational tools and technologies used in the target discipline have to encourage students to independently meet different educational challenges (Tyurina, 2007).

Apart from this, the linguodidactic process is based on the fact that students of teacher-training departments and universities are fully aware of the social nature of their future profession and are determined to successfully socialize, both personally and professionally. The reason for such a process is defined by students' targeted activity that shows personally and socially relevant results.

\section{Results}

Educational processes are perfected through the implementation of modern computer technologies which prompts foreign language teaching professionals to use interactive multimedia materials to their full potential and turn to the blended educational model (Vikulova et al., 2018). Besides, it is essential to 
properly design the general resource architecture in the form of hierarchy of relatively small, logically isolated parts (sections) with simple and informative navigation.

Within the framework of collaborative educational setting we designed and tested a study aid for French language learning based on creative reading of a philosophical novella "The Little Prince" by Antoine de Saint-Exupéry. The study aid gives considerable room for presenting authentic text along with various interactions. Apart from this, the literary piece dictates a fixed learning sequence while incorporating the use of information that contains cultural and cross-cultural content. The key didactic feature of this study aid is multimediality which ensures higher learning motivation.

Current realities for how to set up e-learning process within the context of a pandemic establish a new way of encouraging students to work in a collaborative educational setting, and it becomes a crucial characteristic of highly-qualified teaching professional when teaching the French language. Collaboration means working together to achieve a common goal, a process in which active subjects are committed to cooperating with each other and reach consensus on how to solve the task at hand (Leschenko \& Kapustyan, 2013). The main characteristics that determine relationship between the collaborative group participants are as follows: on the one hand, it is defined by democratic nature, equality, and autonomy. On the other hand, it involves cooperation with other team members during the learning process, discussion of plans and results with the teacher-instructor. Individual task completion does not lay the groundwork for the collaborative learning, on the contrary, it is based on the dynamic cooperation development within the collaborative group. Such an approach does not downplay the responsibility of each team member for fulfilling the assignment. We should point out that within the context of collaborative learning, the role of an individual changes in the cooperation time space depending on the nature of study materials and/or respective assignments (Ibid.)

Along with this, informatization plays a major role in ensuring the quality of modern foreign language education. Implementation of rapidly developing interactive programs, which, for instance, include interactive whiteboards, changes the forms and contents of the learning process, entails changes in methods and transforms approaches to software development. This technology is supported by such cutting-edge programs as Miro, Twiddla, Trello, Notion, Jura, Whiteboard, etc. The term interactive whiteboard has many synonyms: interactive online whiteboard, online whiteboard, online whiteboard for teaching, etc. Along with its main function (its use in class as an alternative to the traditional blackboard), such interactive whiteboards fulfil other crucial functions, and the key one is to manage interactive team work among students (Interactive Whiteboards and Learning, 2006). Relying on such a feature during the process of creative reading ensures that all participants to the learning process stay actively involved and 
make their work even more efficient. The capabilities of the interactive whiteboard are extensively covered in many Russian academic papers (E.I. Passov N.E. Kuzovleva, G.A. Kitaygorodskaya, E.S. Polat, etc.), as well as in foreign ones (P.J. Perry, B. Natoli, S. Hunt, M. Carrier, R.M. Damerow, K.M. Bailey etc).

The review of the latest academic papers allows us to define the team work with the use of an interactive whiteboard in university classes as a form to manage interactive learning activity that involves two or more students who are supposed to work on an assignment based on cooperation principles and students' initiative to exercise their foreign language skills. Interactive whiteboard is a tool that teachers can use to engage their students with their teaching strategies and to participate in the lesson or group practice (Schmid, 2017). It implies that the goal of the team work cannot be reduced to the end product of the fulfilled assignment, as another objective is to teach students to follow communication and cooperation principles, which proves the efficiency of the collaborative approach.

When defining the term creative reading, let us address the Dictionary-Reference Book for Reading (V.A. Borodina, S.M. Borodin): “creative reading is oriented to develop reader's creative skills which manifest themselves when the reader makes his/her own intellectual, informational and cultural content based on what s/he has read (verbal and creolized texts, descriptive and media texts, stage adaptations, sculpture and other artefacts)" (Borodina \& Borodin, 2017). The issue of creative reading is multifaceted as the meaning of the term contains different components: the ability to rise to understanding the author's model of the human and the world while reading, understanding how an image can self-expand to the scale of the limitless Universe, grasping one of the main issues of the literary work which is to gain insight into your own self, see yourself as someone else, explore the existence of someone else's "you". The creative art of reading inspires the creative art of thinking while reading and thinking are complementary (Leader $\&$ Bhatia, 2017). Creative reading is one of the main ways to grasp the paradoxical nature of the human mental world, and at the same time it is a way to become self-confident, understand how unique your mental world is, as the focus of studying shifts towards creativity (Grinberg).

The aforementioned factors of the creative reading process are vital when reading and analyzing philosophical novella "The Little Prince" by Antoine de Saint-Exupéry. This literary work represents a unique phenomenon in global culture and its moral and cultural contents serve as a beacon in educational system. Specifically, the designed study aid would ensure that the novella is approached from a correct professional point of view, which is based on the knowledge of the text as well as on the ability to create secondary texts and to interpret the deep meaning within the book in the context of present day realities. 
We opted for Miro interactive whiteboard to help students develop creative reading skills. With its help you can manage project and team work, visualize the learning process and teach interactive classes. The program is convenient because there is no need to download and install it, and all participants to the collaboration can work from a browser. One of the key features of the program is that it has a free plan for both teachers and students so that they can continue working with texts from the study aid. Besides, the plan includes up to three editable boards for one account which is usually enough for the work of a collaborative group. The teacher creates the project structure and allows students access to the created board via a web-link.

Let us name a few advantages of the Miro whiteboard that make team work efficient and multifaceted in collaborative educational setting within the context of e-learning:

- $\quad$ adding files of different format (presentations, text documents, Excel documents);

- inserting hyperlinks and illustrations;

- drawing on the board;

- $\quad$ adding voice messages and video clips;

- $\quad$ saving the study materials or materials designed both by the teacher and students in PDF format or as graphic images;

- allows team work when the Internet mode ensures that students are involved in authentic context that reflects practical application of language skills;

- commenting on your own or group projects, allowing possible assessment from the teacherinstructor as well as from fellow students.

We have tested several student cooperation formats on creative reading of the study aid for philosophical novella "The Little Prince" by Antoine de Saint-Exupéry while using the Miro interactive whiteboard:

1. Interactive study aid.

The teacher uploads novella's chapters, study materials (video and audio materials), and test assignments to the board. All the participants work remotely under the supervision via Microsoft Teams platform. The teacher shares his/her screen, demonstrates and actively discusses the study aid texts and images. Another possible way of work is when the collaborative team members independently study the board in a mode that is managed by the teacher. 
We rely on the Miro whiteboard as a study aid throughout the course, posting all necessary materials on the one board which allows teachers and students access to all completed tasks and ensures easy navigation between classes. When working with texts, going through additional materials and browsing cross-cultural content, students create their own intellectual, informational and cultural products directly on the board. It might be a presentation, a video clip, a quest or a test. Thus, the students' work acquires creative and dynamic nature while the teacher gets an opportunity to observe and collaborate.

\section{Discussion.}

The teacher forms questions related to the content of the selected chapters, provides a general work plan, uploads all the needed materials to the board: audio and video materials created on the basis of "The Little Prince" novella. Specifically, we offer text adaptation used in the French musical. In this case the future of the literary work becomes crucial as it is dependent on the readers' and viewers' reception as well as on the author's literary reputation. The existence of the literary text in a different cultural space shows that it is possible for two texts, the original text and the one adapted according to its new form, can actually coexist and cooperate with each other. Thus, the suggested assignment calls for a different visual interpretation of the text:

Could we say that such art forms prompt us to search for and choose from those values and moral standards that would help us relate global cultural values to the perception that children have today? Provide brief arguments to support you point of view.

Student voice their opinion via stickers, and the teacher observes how their thoughts develop in real time, then we sum up the results and revisit voiced ideas to introduce certain changes.

\section{Team work.}

The program also allows us to successfully arrange teams so that they could work on a certain project. The suggested assignments are based on the problem-solving and dialogic principles. The Miro whiteboard enables students to go through the tasks, study the suggested additional material and then put a joint project solution up for discussion. For instance, here is one of the assignments that requires the use of the Miro interactive white board: the teacher provides the description of the key characters who The Little Prince met on his journey, and students have to put them in their respective place on the timeline. Next, students have to voice their personal opinion on the characters and answer moot questions. 
The suggested tests and communication-oriented assignments determine the reading strategy as well as help form personal view on what has been read. The key feature of the following working format is sophisticated nature of the study material and that the learning activity management is aimed at creative knowledge acquisition while combining linguistic and cultural aspects. Apart from this, we focus on the following idea: when perceiving the literary work in the foreign language from another culture, people are not only enriched with the language knowledge, but also expand their individual map of the world.

It is essential for students to realize that a literary work can transform into a secondary art-object when, for example, the visual interpretation of the text is embodied in urban sculpture and architecture. In this case we see how literary culture merges with urban science, how literature "incorporates" itself in urban space, which opens new opportunities for the visualization of a literary text. For instance, the following assignment featured in our study aid aims at understanding how the dialogue between the author and readers works:

Do you agree or do not agree with the statement that the presence of a literary character in urban setting forms the framework of the urban resident's spatial experience and reflects the fusion of literature and art? Do these art-objects enhance the appeal of reading books? Make up a presentation to support your point of view.

Thus, the synthetic approach to researching the existence of a literary text in cultural space can serve as a tool for further scientific developments of multidisciplinary nature.

\section{Discussions}

The implementation of modern web-technologies expands the range of learning activities and makes adoption of new teaching organizational forms and methods possible. The research into the capabilities of an interactive language course within the framework of the blended educational model shows that electronic learning resource (ELR) widens teachers' creative opportunities and allows them to train successful, independent, self-reliant students.

Due to the implementation of the ELR (in our case, the Miro program) the features of the open-type online assignments (creative assignments) are used to their full potential. Thus, the blended educational model can be successfully applied to both traditional and intensive French classes.

\section{Conclusion}


Cutting-edge technologies facilitate the development of the new teaching organizational forms and methods. The analysis of teaching the French language while using a study aid together with interactive programs shows that such a combination expands teachers' creative horizons and ensures that students are extrinsically motivated when learning foreign languages in higher school.

The research allows us to name the following major advantages of the use of the Miro interactive whiteboard in teaching creative reading while using the study aid for the philosophical novella "The Little Prince" by Antoine de Saint-Exupéry:

- authentic context that ensures learning motivation;

- possible analysis of the cultural component of a life of a different linguistic community, development of a linguocultural competence in students;

- cooperative participation when teamwork facilitates students' creative development and prompts them to solve problems and make decisions together;

- the lack of time and space restrictions which allows students of different activity level and speed to work autonomously, thus acquiring more knowledge and boosting their self-esteem and confidence.

We should note that despite all the challenges that teachers meet when working with the interactive whiteboard (time-consuming lesson planning, the software and interactive whiteboard incompatibility, the required level of computer skills of both teachers and students), its implementation into the educational process, especially together with collaborative learning, significantly facilitates the development of the foreign language communicative competence.

With the help of the Miro program creative online assignments are exercised to their full potential. Along with this, the e-learning model within the framework of a collaborative educational setting can be applied to both traditional and intensive French classes.

The use of the aforementioned electronic learning resource aims at reconsidering the goals and objectives of modern teachers who perform their professional activities in the dynamic and ever-changing world. Modern technologies are considered to actively enhance the quality of the educational process and are vital for developing professional competencies in students as prospective teachers.

\section{Acknowledgements}


We especially want to thank the dedicated practitioners who shared their expertise and to the pupils for their views. We are also grateful to the Economic and Social Research Council for funding both the InterActive Education and SET-IT projects.

\section{References}

Auer, Michael E., \& Tsiatsos Thrasyvoulos (2019) The Challenges of the Digital Transformation in Education: Proceedings of the 21st International Conference on Interactive Collaborative Learning (ICL2018) - Vol. 1, 982.

Borodina, V. A., \& Borodin, S. M. (2017). Slovar-spravochnik po chteniu: praktikum [Reading guide: case study]. M.: RShBA, 231.

Carrier, M., \& Damerow, \& R.M., \& Bailey K.M. (2017) Digital Language Learning and Teaching: Research, Theory, and Practice. Taylor \& Francis, 264.

Cazden C.B. (2017). Communicative Competence, Classroom Interaction, and Educational Equity: The Selected Works of Courtney B. Cazden. Routledge, 264.

Grinberg, B. M. (2021, January 09) Chitatelskiy dnevnik kak tekhnologiya kreativnogo chtenia i kak instrument razvitiya chitatelskoy kultury podrostka [Reading log as a creative reading technology and as a tool promoting teenager's reading culture]. Retrieved from https://xn--80acgfbsl1azdqr.xn-p1ai/file/1be6adb071dd68bbb5cf6f819ddc2afc

Interactive Whiteboards and Learning. Improving student learning outcomes and streamlining lesson planning (2006, January 21). from http://downloads01.smarttech.com/media/education/pdf/interactivewhiteboardsandlearning.pdf

Leader, S., \& Bhatia, P. Creative Reading: Reading Makes a Man. (2017). Partridge Publishing, 226

Leschenko, M. P., \& Kapustyan, I. I. (2013) Informatizatsiya neprerivnogo pedagogicheskogo obrazovaniya v Shvetsii [Lifelong teacher-training education informatization in Sweden]. Obrazovatelinie tekhnologii i obschestvo [Educational technologies and the society], Vol.16, 1, 800-845.

Natoli, B., \& Hunt, S. (2019) Teaching Classics with Technology. Bloomsbury Publishing, 264. 
Ovchinnikova, E. N. (2012) K opredeleniu terminov "uchebnik" i "uchebnoe posobie" [About Definition of the Terms "Textbook" and "Manual"]. Gumanitarnie nauchnie issledovania [Humanitarian scientific research], 5. Retrieved from http://human.snauka.ru/2012/05/1189

Perry, P. J. (2019) Technology Tips for Ensemble Teachers. Oxford University Press, 256.

Puren, Ch. (2009) La nouvelle perspective actionnelle et ses implications sur la conception des manuels de langue. Analyse des mini-projets terminaux des unités didactiques de Rond-point 1 (Diffusión 2004). L'approche actionnelle dans l'enseignement des langues. Onze articles pour mieux comprendre et faire le point. Barcelone: Difusión-Édition Maison des langues, 119-137.

Riquois, E. (2011) Evolutions méthodologiques des manuels et matériels didactiques complémentaires en FLE: De la méthode traditionnelle à la perspective actionnelle// Education \& Formation, 296, 129-142.

Saharova, E. G., \& Kletskaya, Z. M. (2007) Postroenie strukturi materiala v uchebno-metodicheskom izdanii [Forming architecture in educational materials]. Izvestia visshikh uchebnikh zavedeniy. Problemi poligrafii $i$ izdatelskogo dela [Bulletin of Higher Education Institutions. Problems of Printing and Publishing], 5, 75-80.

Schmid, E.C. (2017) Teacher Education in Computer-Assisted Language Learning: A Sociocultural and Linguistic Perspective. Bloomsbury Publishing, 224.

Tareva, E. G. (2015). Razvitie lingvoobrazovatel'nyh praktik: optimistichnaya proekciya [Evolution of Foreign Language Teaching Practices: Optimistic Projection]. Vestnik Moskovskogo gorodskogo pedagogicheskogo universiteta. Seriya: filologiya. Teoriya yazyka. Yazykovoe obrazovanie [Bulletin of the Moscow City Pedagogical University. Series: Philology. Language theory. Language education], 2 (18), $75-85$.

Tareva E. G., \& Tarev B. V. (2018) The Assessment of Students professional communicative Competence: New Challenges and possible Solutions. XLinguae, Vol. 11, 2. 758-767. doi: 10.18355/XL.2018.11.02.59

Toruç, D. (2013) Comment peut-on faire développer l'autonomie des étudiants en classe de langues étrangères surtout en classe de FLE? // Turkish Studies - International Periodical for The Languages, Literature and History of Turkish or Turkic, Vol. 8/10, 659-669.

Vikulova, L. G., \& Makarova, I. V., \& Gerasimova, S. A. (2018) Features of iSpring Suite learning platform for teaching foreign languages // Espacios, Vol. 39, 20, 5. 